\section{Contribution of Root and Shoot Tissues of Phaseolus vulgaris to Meloidogyne incognita Resistance}

\author{
B.A. Mullin and G.S. Abawi \\ Department of Plant Pathology, Cornell University, New York State \\ Agricultural Experiment Station, Geneva, NY 14456
}

\section{M.A. Pastor-Corrales and J.L. Kornegay \\ Bean Program, Centro Internacional de Agricultura Tropical, Apartado Aéreo 6713, Cali, Colombia}

Additional index words. bean, stem graft

\begin{abstract}
A stem grafting technique was used to determine the contribution of root and shoot tissues of bean (Phaseolus vulgaris $L_{\text {.) }}$ to the resistance response to the rootknot nematode, Meloidogyne incognita (Kofoid and White, 1919) Chitwood 1949. Stemgrafts were prepared between resistant (line A 211 or cultivar Nemasnap) and susceptible (Canario Divex) bean cultivars in all possible scion-rootstock combinations. Graft combinations in which the rootstock was resistant resulted in a resistant response to $M$. incognita, and those combinations in which the rootstock was susceptible resulted in a susceptible response, regardless of scion component. Resistance factors were therefore either localized within roots or not translocated basipetally through the stem graft union.
\end{abstract}

Dry edible beans are an important crop for low- to middle-income farmers in much of Latin America and Africa. However, bean yields are low in Latin America, averaging $\sim 600 \mathrm{~kg} \cdot \mathrm{ha}^{-1}$, compared with average yields in the United States of $1500 \mathrm{~kg} \cdot \mathrm{ha}^{-1}$ (Pachico, 1989). Plant diseases account for much of this yield reduction. In a recent study, root-knot nematodes (Meloidogyne spp.) were found infecting beans throughout the major bean production areas of Colombia and Peru, causing yield losses of $24 \%$ to $63 \%$ (Mullin et al., $1991 \mathrm{c}$ ). Because of the severe nature of root-knot nematode attack on beans in these areas, 200 bean accessions and pure lines were screened for resistance to root-knot nematodes (Mullin et al., 1991 b). An understanding of the resistance factor(s) and its inheritance would aid bean breeders in transferring this resistance into commercially accepted and locally adapted bean cultivars for use in the Andean-zone countries.

Received for publication 7 Dec. 1990. Support for B.A.M. while at CIAT was provided by the Fellowships and Training Program of the Organization of American States. The authors wish to thank Jeff White for advice on the grafting technique and Guillermo Castillanos for technical assistance. The cost of publishing this paper was defrayed in part by the payment of page charges. Under postal regulations, this paper therefore must be hereby marked advertisement solely to indicate this fact.
Disadvantages to standard nematode resistance screening procedures are the long period needed to obtain resistance information and the large amount of greenhouse or field space required for this duration. Additionally, standard procedures are destructive; thus, when seeds from resistant plants are desired, evaluations must be postponed until seed maturity. Root explants have been used to study host-parasite relationships in beans to Meloidogyne incognita. grafted plant. or $>100$ egg masses per root system.

${ }^{x}$ Resistance index $=$ (root galling rating ${ }^{2}+$ egg mass rating ${ }^{2}$ ). incognita, respectively. some nematode-plant systems (Guy and Lewis, 1987; Lauritis et al., 1982). For these reasons, an alternative procedure for rootknot nematode resistance screening using root explants was attempted (Mullin, 1990). However, reactions of resistant and susceptible bean germplasm were less distinct with this technique than with pot tests. Stem grafts of bean plants have been successfully used to study the influence of root and shoot genotypes on bean yield under drought stress or for other purposes (White and Castillo, 1989). We used a stem graft technique to determine whether shoot tissues influence the expression of resistance in root tissues.

Stem grafts were prepared according to White and" Castillo (1989): Bean seeds were sown individually in cell packs within flats in a growth chamber (12-h photoperiod, $21 \mathrm{C}$ ). Shoot portions of 7- to 9-day-old bean seedlings were excised 1 to $2 \mathrm{~cm}$ below cotyledonary nodes using a single-edged razor. Two additional diagonal cuts were made in the stem of the scion to form a wedge. Rootstock were prepared by excising shoot portions as for scions, and a verticial incision was made in the stem to accommodate the prepared stem of the scion. The graft unions were sealed with strips of parafilm. Plants were allowed to harden for 2 to 3 days under low light conditions. Bean germplasm included the resistant line A 211 and the resistant 'Nemasnap', and susceptible 'Canario Divex' (Mullin et al., 1991 b). Treatments consisted of susceptible and resistant germplasm in all scion-rootstock combinations, self grafts, and nongrafted plants. Where the treatment was a self graft (e.g., both scion and rootstock from A 211), the scion was obtained from a different rootstock plant than

Table 1. Reaction of stem-grafted resistant (A 211 and 'Nemasnap') and susceptible ('Canario Divex')

\begin{tabular}{lcccc}
\hline \hline Graft combination & $\begin{array}{c}\text { Galling } \\
\text { rating }\end{array}$ & $\begin{array}{c}\text { Egg mass } \\
\text { rating }\end{array}$ & $\begin{array}{c}\text { Resistance } \\
\text { index }^{\mathbf{x}}\end{array}$ & $\begin{array}{c}\text { Reaction } \\
\text { class }^{\mathbf{w}}\end{array}$ \\
\hline A 211/Canario Divex & 8.0 & 7.8 & 124.8 & $\mathrm{HS}$ \\
Canario Divex/A 211 & 1.0 & 1.0 & 2.0 & $\mathrm{Im}$ \\
Nemasnap/Canario Divex & 8.3 & 7.8 & 128.5 & $\mathrm{HS}$ \\
Canario Divex/Nemasnap & 1.0 & 1.0 & 2.0 & Im \\
A 211/A 211 & 1.3 & 1.0 & 2.8 & $\mathrm{HR}$ \\
A 211 & 1.0 & 1.0 & 2.0 & Im \\
Nemasnap/Nemasnap & 1.3 & 1.0 & 2.8 & $\mathrm{HR}$ \\
Nemasnap & 1.3 & 1.3 & 3.5 & $\mathrm{HR}$ \\
Canario Divex/Canario Divex & 9.0 & 8.0 & 145. & $\mathrm{HS}$ \\
Canario Divex & 7.5 & 8.0 & 120. & $\mathrm{HS}$ \\
LSD $_{0.05}$ & 1.6 & 1.4 & 34.8 & \\
\hline
\end{tabular}

${ }^{2}$ Graft combination where numerator represents scion and denominator represents rootstock, or non-

y Based on a scale where $1=$ no root galling or no egg masses produced, $9=76 \%-100 \%$ roots galled

"Im, HR, and HS refer to immune, highly resistant, and highly susceptible reactions to Meloidogyne 


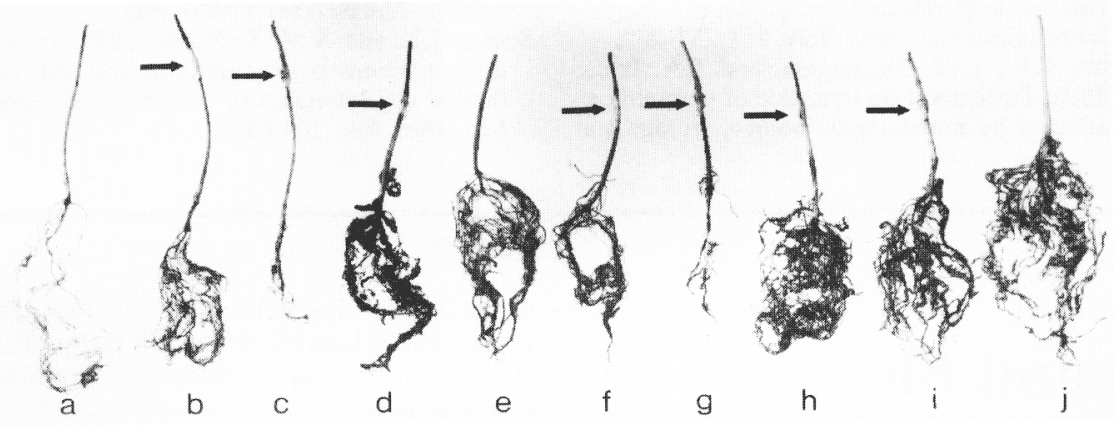

Fig. 1. Influence of scion source on root galling severity (rating) induced by Meloidogyne incognita in Phaseolus vulgaris. Graft combinations are (a) A 211 (resistant), nongrafted (1.0); (b) A 211 scion on A 211 rootstock (1.3); (c) 'Canario Divex' (susceptible) scion on A 211 rootstock (1.0); (d) A 211 scion on 'Canario Divex' rootstock (8.0); (e) 'Nemasnap' (resistant), nongrafted (1.3); (f) 'Nemasnap' scion on 'Nemasnap' rootstock (1.3); (g) 'Canario Divex' scion on 'Nemasnap' rootstock (1.0); (h) 'Nemasnap' scion on 'Canario Divex' rootstock (8.3); (i) 'Canario Divex' scion on 'Canario Divex' rootstock (9.0); (j) 'Canario Divex', nongrafted (7.5). Arrows indicate location of graft unions. Graft combinations of 'Canario Divex' scion and A 211 (c) or 'Nemasnap' (g) rootstock resulted in dwarf phenotypes.

that to which it was grafted. Each treatment was replicated four times. Ten days after grafting, seedlings were transplanted into 0.5 Iiter pots, and a suspension of 10,000 eggs of $M$. incognita was applied as a drench to each root system. Eggs had been extracted with $\mathrm{NaOCl}$ (Hussey and Barker, 1973), and were obtained from a population collected near Popayán, Colombia, that had been increased on tomato (Lycopersicon esculentum Mill.) in the greenhouse. Roots were then covered with soil and plants were grown in the chamber for an additional 8 weeks. Plants were harvested by removing shoot portions and carefully washing soil from roots. Root galling severity was assessed by estimating the proportion of roots galled: $1=$ no galling, $2=<5 \%$ roots galled, $3=6 \%-10 \%$, $4=11 \%-18 \%, 5=19 \%-25 \%, 6=26 \%$ $50 \%, 7=51 \%-65 \%, 8=66 \%-75 \%$, and $9=76 \%-100 \%$ roots galled. Egg mass production was also assessed on a scale where: $1=$ no egg masses detected, $2=$ one to two egg masses, $3=$ three to six, $4=$ seven to $10,5=11-20,6=21-30,7=31-60$, $8=61-100$, and $9=>100$ egg masses per plant. A resistance index (RI) was calculated to incorporate both parameters of resistance (reduced root galling severity and nematode egg mass production) into a single value, according to: $\mathrm{RI}=$ (root galling severity rating $^{2}+$ egg mass rating ${ }^{2}$ ). In this scheme, the reaction of a plant to root-knot nematodes was classified as follows: RI of $2=$ immune, RI of 3-8 = highly resistant, RI of 9-18 = resistant, RI of 19-32 = moderately resistant, RI of 33-50 = intermediate, RI of 51-72 = moderately susceptible, RI of 73-98 = susceptible, and RI of 99162 = highly susceptible (Mullin et al., 1991b).

Root galling severity and egg mass ratings were concurrently high or low for any graft combination (Table 1). All scion-rootstock combinations with the resistant source (A 211 or 'Nemasnap') in the rootstock resulted in a resistant reaction to $M$. incognita, regardless of scion source. Where the rootstock was the susceptible 'Canario Divex', the resulting response to $M$. incognita was susceptible. Nongrafted susceptible and resistant bean pure lines responded accordingly for root galling and nematode egg mass production. Graft combinations of susceptible scion on resistant rootstock also resulted in dwarf phenotypes. Representative individuals of these graft combinations are illustrated in Fig. 1.

The factor(s) conditioning resistance to root galling caused by $M$. incognita in both A 211 and 'Nemasnap' were apparently localized within plant roots; bean root tissues alone provided the resistance to $M$. incognita. Either the shoot portion of resistant plants did not affect resistance expression in the root tissues, or resistance factors were not transmitted basipetally through the stem graft union.

Stem galling of 'Nemasnap' and A 211 due to root-knot nematodes has been noted (Fassuliotis and Deakin, 1973; B.A.M., unpublished), suggesting that the resistance factor(s) is root-borne. These data strongly support this conclusion for 'Nemasnap' and advanced line A 211. A similar root-localized effect has been noted for resistance to M. incognita in cotton (Gossypium hirsutum L.) (McClure et al., 1974) and tomato (Riggs and Winstead, 1958). A dosage-dependent dwarfing phenotype as previously reported in the literature (Singh, 1989; Singh and Gutiérez, 1984) was also observed in all graft combinations involving the susceptible 'Canario Divex' as scion and the resistant A 211 or 'Nemasnap' as rootstock. Although the dwarfing phenotype resulted in restricted root and shoot growth, the expression of resistance to $M$. incognita was not affected by this factor.

These results suggest that it should be pos- sible to select for resistance to root-knot nematodes in beans using root explants. Factors other than presence of shoot tissue, such as incubation temperature (Mullin et al., 1991a) and culture media selection may have contributed. to the lower level of resistance exhibited by bean root explants relative to whole-plant studies. Further studies in these areas are likely to result in a suitable method by which excised bean root tissues can be used for root-knot nematode resistance screening.

\section{Literature Cited}

Fassuliotis, G. and J.R. Deakin. 1973. Stem galls on root-knot nematode resistant snap beans. J. Amer. Soc. Hort. Sci. 98:425-427.

Guy, D.W. and S.A. Lewis. 1987. Selective migration and root penetration by Meloidogvne incognita and Hoplolaimus columbus on soybean roots in vitro. J. Nematol. 19:390-392.

Hussey, R.S. and K.R. Barker. 1973. A comparison of methods of collecting inocula of Meloidogyne spp., including a new technique. Plant Dis. Rptr. 57:1025-1028.

Lauritis, J.A., R.V. Rebois, and L.S. Graney. 1982. Screening soybean for resistance to Heterodera glycines Ichinohe using monoxenic cultures. J. Nematol. 14:593-594.

McClure, M.A., K.C. Ellis, and E.L. Nigh. 1974. Resistance of cotton to the root-knot nematode, Meloidogvne incognita. J. Nematol. 6:17-20.

Mullin, B.A. 1990. Ecology and host-parasite relationships of root-knot nematodes (Meloidogyne spp.) infecting dry edible beans (Phaseolus vulgaris L.) in Colombia and Peru. PhD Diss., Cornell Univ., Ithaca, N.Y.

Mullin, B.A. G.S. Abawi, and M.A. Pastor-Corrales. 1991a. Modification of resistance expression of Phaseolus vulgaris to Meloidogyne incognita by high soil temperatures. J. Nematol. 23:182-187.

Mullin, B. A., G.S. Abawi, M.A. Pastor-Corrales, and J.L. Kornegay. 1991b. Reactions of selected bean pure lines and accessions to $\mathrm{Me}$ loidogine species. Plant Dis. 75:1208-1211.

Mullin, B. A., G.S. Abawi, M.A. Pastor-Corrales, and J.L. Kornegay. 1991c. Root-knot nematodes associated with beans in Colombia and Peru and related yield loss. Plant Dis. 75:1212-1216

Pachico, D. 1989. Trends in world common bean production, p. 1-8. In: H.F. Schwartz and M.A. Pastor-Corrales (eds.). Bean production problems in the tropics, 2nd ed. Ccntro International de Agricultural Tropical: Cali, Colombia.

Riggs, R.D. and N.N. Winstead. 1958. Attempts to tranfer root knot resistance in tomato by grafting. Phytopathology 48:344. (Abstr.)

Singh, S.P. 1989. Patterns of variation in cultivated common bean (Phaseolus vulgaris, Fabaceae). Econ. Bet. 43:39-57.

Singh, S.P. and J.A. Gutiérez. 1984. Geographical distribution of the $\mathrm{DL}_{1}$, and $\mathrm{DL}_{2}$ genes causing hybrid dwarfism in Phaseolus vulgaris L., their association with seed sizes, and their significance to breeding. Euphytica 33:337-345.

White, J.W. and J.A. Castillo. 1989. Relative effect of root and shoot genotypes on yield of common bean under drought stress. Crop Sci. 29:360-362. 